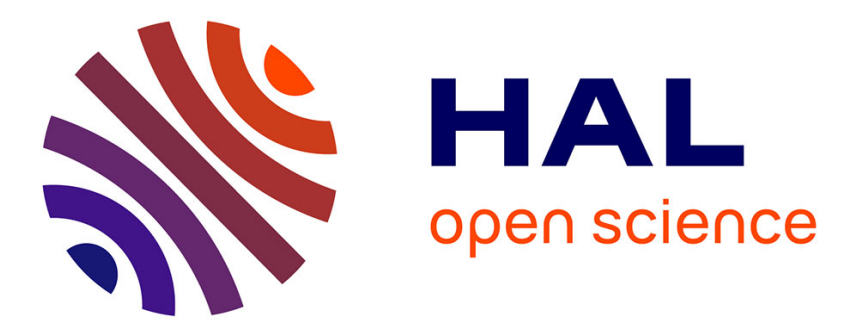

\title{
Humans and climate as possible drivers of the morphology and function of the mandible of Suncus etruscus in Corsica
}

\author{
Miranta Kouvari, Anthony Herrel, Raphaël Cornette
}

\section{To cite this version:}

Miranta Kouvari, Anthony Herrel, Raphaël Cornette. Humans and climate as possible drivers of the morphology and function of the mandible of Suncus etruscus in Corsica. Journal of Archaeological Science, 2021, 132, pp.105434. 10.1016/j.jas.2021.105434 . hal-03365343

\author{
HAL Id: hal-03365343 \\ https://hal.science/hal-03365343
}

Submitted on 13 Oct 2021

HAL is a multi-disciplinary open access archive for the deposit and dissemination of scientific research documents, whether they are published or not. The documents may come from teaching and research institutions in France or abroad, or from public or private research centers.
L'archive ouverte pluridisciplinaire HAL, est destinée au dépôt et à la diffusion de documents scientifiques de niveau recherche, publiés ou non, émanant des établissements d'enseignement et de recherche français ou étrangers, des laboratoires publics ou privés. 
1 Humans and climate as possible drivers of the morphology and function of the mandible of

2 Suncus etruscus in Corsica.

3 Miranta Kouvari ${ }^{1,2,3}$, Anthony Herrel ${ }^{4} \&$ Raphaël Cornette $^{1}$

$4 \quad{ }^{1}$ Institut de Systématique, Evolution, Biodiversité (ISYEB), UMR 7205 Muséum National D'Histoire

5 Naturelle, CNRS, Sorbonne Université, EPHE, Université des Antilles, CP 50, 57 rue Cuvier, 75005 Paris,

6 France

$7 \quad{ }^{2}$ Department of Earth Sciences, University College London, Gower Street, WC1E 6BT, London, United

8 Kingdom.

$9{ }^{3}$ Life Sciences Department, Vertebrates Division, Natural History Museum, SW7 5BD, London, United 10 Kingdom.

$11{ }^{4}$ UMR 7179 - CNRS/MNHN, Bâtiment d'Anatomie Comparée, 55 rue Buffon, CP 55, 75005, Paris, France.

12 Corresponding author: Miranta Kouvari (miranda.kou@gmail.com). 


\section{Abstract}

14 Human-induced environmental changes have increased rapidly during the Holocene and have reached

15 alarming levels today. Consequently, it is crucial to better understand the impact of humans and

16 climate on the faunas and floras through time. Understanding the direct and underlying effect of past human activity not only contributes to improving our knowledge of human history but also provides insights for the future. We here investigate the effect of the human-induced environmental changes that took place during the modern era $\left(14-19^{\text {th }}\right.$ century $\left.A D\right)$ on the mandible of a small mammal, Suncus etruscus, in Corsica. We detected rapid morphological changes in mandible shape over the relatively short period of time included in our study, suggesting a strong human impact on the island. The morphological changes observed had functional consequences as they are related to changes in the mechanical potential of the principal masticatory muscle, the temporalis that, in turn, reflects shifts in the animal's diet over time. These results highlight the effect that the 600-year human agricultural activity shifts had on the island and its fauna. The integration of the body and the ramus of the mandible appears to be related to the mechanical potential of the temporalis muscle but does not constitute an indicator of human-induced environmental change. Whether these morphological changes are the result of natural selection (genetic processes) or of phenotypic plasticity (epigenetic processes) remains to be elucidated.

Keywords: Mandible; Morphometrics; Shape; Bite force; Corsica; Shrew; Integration 
We live in an era of rapid and global environmental change where man is the principal driver of changes in the environment, largely because of the expansion of industry and agriculture, as well as population growth (Vitousek et al., 1997). The impact of humans on natural ecosystems has dramatically increased from the Holocene to recent times and has gone hand in hand with climate change. This has had enormous repercussions on ecosystems worldwide (Barnosky et al., 2004) resulting in the so-called sixth mass extinction (Pimm \& Brooks, 2000; Barnosky et al., 2011; MacPhee \& Sues, 2013; Ceballos et al., 2015). It is therefore crucial to better understand past human activity in conjunction with its direct and indirect impacts on natural landscapes and the organisms that inhabit these. The study of past environmental changes and their impact on fauna and flora may provide us with valuable insights for the future (Blois \& Hadly, 2009). Understanding the direct and indirect effects of past human activity on ecosystems provides valuable information that not only improves our understanding of human history but also provides insights on how human activity can impact future ecosystems.

An important aspect is the phenotype of an organism as it typically reflects the environmental context it lives in as form (shape and size) is intimately linked to function (Anderson et al., 2008). For example, the form of the mandible is intimately linked to bite force generation and may thus provide insights into diet, anti-predator defense and/or competition in animals (Anderson et al., 2008). As such, mandible shape may be used as a marker of environmental change. This is true for all vertebrates, but especially so for small mammals that are likely constrained in their diet by their absolute bite force (Atchley, 1993; Aguirre et al., 2003; Renaud et al., 2009). As such, we hypothesize that bite force should be related to environmental changes. We also hypothesize that the environmental changes may impact mandibular integration and modularity. Integration is defined as the relation between anatomical structures often referred to as modules. Modules are defined when the different anatomical structures inside the module co-vary more strongly among themselves than with any anatomical structure outside the module (Olson \& Miller, 1958; Klingenberg et al., 2004; Schlosser \& Wagner, 2004; Callebaut \& RasskinGutman, 2005; Mitteroecker \& Bookstein, 2007; Klingenberg, 2008; Goswami \& Polly, 2010). Hanot et al. (2018), for example, found that artificial selection had an impact on the patterns of integration of the appendicular skeleton of domestic horses. Moreover, Hanot et al. (2017) showed that integration is stronger in the cases where functional constraints are strong, suggesting that the degree of integration of the mandible might provide insights in the strength of selection on this structure.

Islands are often considered "natural laboratories" allowing the study of ecosystems in relation to environmental changes as well as a better understanding of evolutionary mechanisms and extinction and speciation events as insular ecosystems are simple and sensitive to changes and moreover (Darwin, 1845; Wallace, 1860; Losos et al., 1997; Whittaker \& Fernández-Palacios, 2007). In this context, the 
65 island of Corsica (Fig. 1a, b) appears a good model to study the relationship between humans and their 66 environment through time and the subsequent impacts thereof on the fauna (Vigne et al., 1997; Vigne, 67 1999). The first arrival of man on most Mediterranean islands took place in the last 12,000 years and 68 this was more often than not, followed by the extinction of endemic species and their replacement with 69 newly introduced taxa (e.g. Alcover et al., 1981; Davis, 1984; Vigne \& Alcover, 1985; Kouvari \& van der 70 Geer, 2018). Corsica is a great example as the impact of humans on the endemic fauna and flora is 71 exceptionally well documented (Vigne, 1990, 1992, 1996, 1999; Vigne \& Valladas, 1996). While the megafauna extinction on Corsica took place soon after the first arrival of man, smaller endemic

73 mammals went extinct much later (Vigne, 1988, 1990, 1992). Humans involuntarily introduced many

74 small mammals that became established on the island (Vigne, 1988, 1990, 1992; Vigne \& Valladas, 75 1996). 

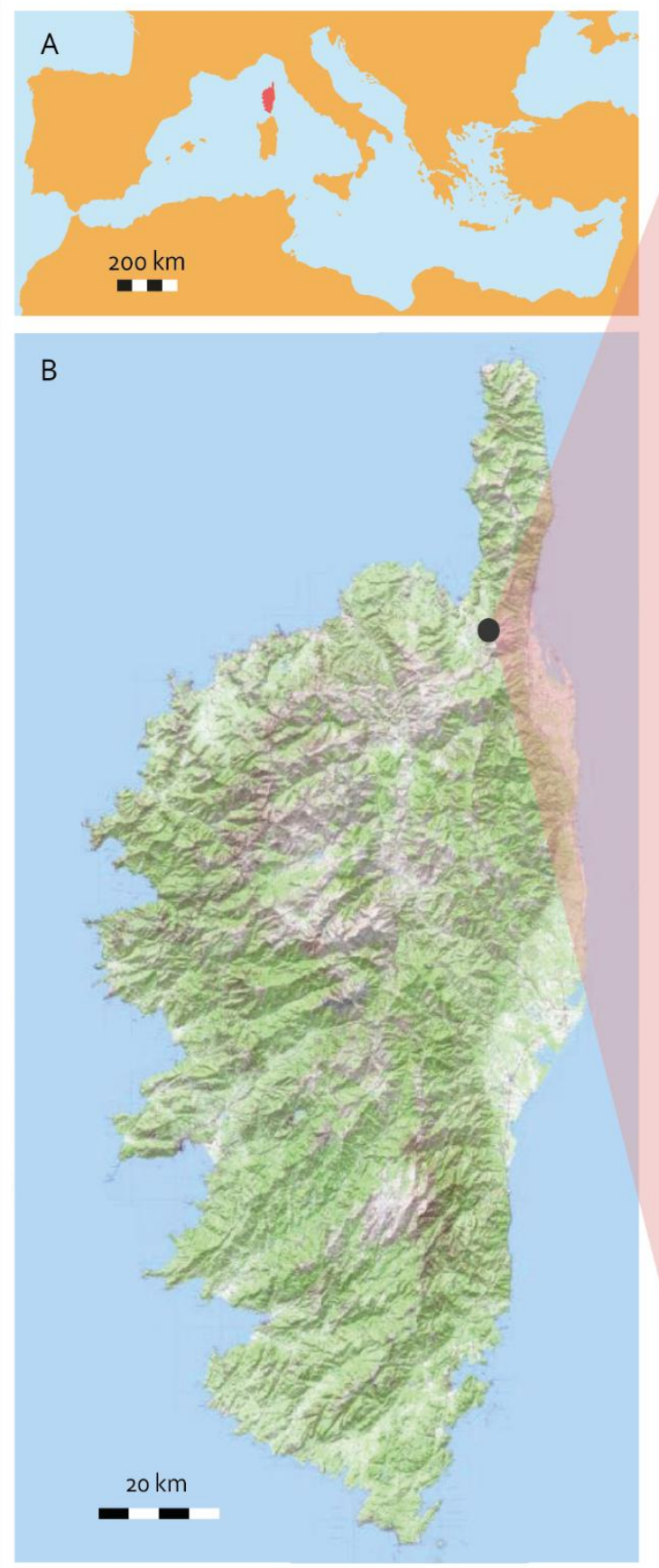

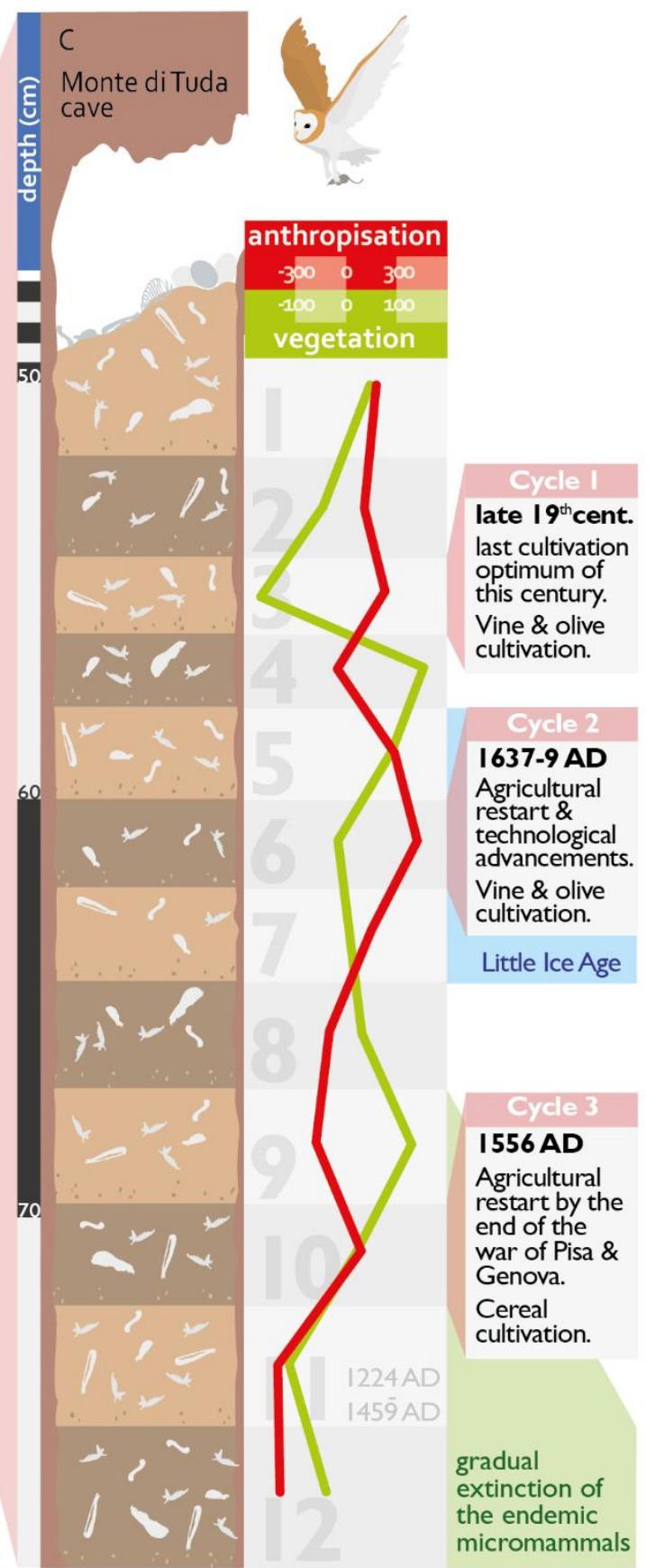

Figure 1. (a) Map of the Mediterranean Sea showing Corsica in red, (b) Geomorphological map of Corsica, and (c) an illustration of the layers of the Monte di Tuda cave, their depth, the vegetation and anthropisation indices and information on the dating, anthropisation cycles and other important events. Modified after Vigne \& Valladas (1996). Mediterranean map based on outlines from (c) d-maps.com. Corsica map from (C IGN Planet Observer.

The Monte di Tuda site is an archaeological site in the Nebbio Basin in the North of the island (Fig. 1a,

b). The site consists of a cave that served as an owl nest (probably Tyto alba) for the last 2500 years and provides an exceptional accumulation of micromammal remains through time (Vigne \& Valladas, 1996). Vigne \& Valladas (1996) studied these remains and the changes therein through time. They distinguished biozones, and calculated an anthropisation and vegetation index for each layer. More specifically, they studied the cave sediment stratigraphy, distinguished the different layers present, and dated $\left({ }^{14} \mathrm{C}\right)$ some of them. They studied the faunal assemblages by calculating the minimum number of 
individuals (MNI) of each species in each layer. Based on the previous and in conjunction with the known ecological preference of the species, they ran a correspondence analysis (CA) between species and layers (their faunal compositions) in order to observe the potentially existing patterns of ecological significance. From this, the first axis distinguished between anthropophilic species while the second between species preferring "natural" medium maquis vegetation and those preferring low vegetation. They thus used the CA layer coordinates of the F1 axis as an anthropisation index and those on the F2 as a vegetation index. Finally, based on those vegetations and anthropisation indices along with the information on the dated layers and the history of Corsica, the authors distinguished anthropisation cycles, characterized by important local events.

This exceptional stratigraphic sequence in Monte di Tuda brought valuable evidence on the landscape, faunal and human evolution in Northern Corsica (Vigne \& Valladas, 1996). Three sub-sequences were identified. The first and oldest one (864-409 BC to 322-283 AD) is characterized by the increase of human-induced impacts (often due to intense cereal cultivation) and habitats consisting of highmedium maquis. The second one (taking place until 1224-1459 AD) is characterized by an acceleration of human impacts in the region coupled with clearing of vegetation. Finally, the third and last subsequence includes a drastic intensification of deforestation resulting in a landscape not very different of that of today. The extinction of the endemic small mammals is also recorded in this sub-sequence at this last step and is hypothesized to have happened due human-induced habitat alteration in northern Corsica (Vigne \& Valladas, 1996). This last sub-sequence is the focus of our study (Fig. 1c).

Small mammals are often good markers of the environment they live in (Bar-Yosef \& Tchernov, 1966; Brothwell \& Jones, 1978; Chaline, 1979; Marquet, 1989; Rofes et al., 2014; Weissbrod, 2010; Stoetzel et al., 2011). We studied one of the smallest species, the white-toothed shrew Suncus etruscus (Savi, 1822) (Soricidae) (Fig. 2a). This shrew is one of the smallest extant mammals by mass (only $1.8 \mathrm{~g}$; Jürgens, 2002) and reached Corsica, as well as most other Mediterranean islands, through humanmediated transport (Dobson, 1998; Chen \& Koprowski, 2018). It is a synanthropic/anthropophilic species as it thrives in human-transformed habitats such as olive groves and vineyards (Dobson, 1998). It is an opportunistic species feeding principally on invertebrates but also occasionally on small vertebrates (Nowak \& Paradiso, 1999; Kingdon et al., 2013). We here specifically focus on its mandible (Fig. 2a) as this structure is directly linked to diet (Badyaev \& Foresman, 2004) and interspecific competition (Cornette et al., 2015c) through its impact on bite force generation. Shrew mandibles also show exceptional phenotypic plasticity (Young et al., 2010) i.e. non-heritable morphological variation as a response to environmental pressures (Price et al., 2003). Phenotypic plasticity has been investigated in laboratory-raised mice (Anderson et al., 2014; Garland \& Kelly, 2006; Renaud et al., 2010) but has also been observed in shrews fed on different diets (Young \& Badyaev, 2010). Bite force is an 
ecologically relevant performance trait as it is directly related to prey capture and manipulation and as such determines the type and size of prey that can be consumed (Aguirre et al., 2003; Anderson et al., 124 2008). We here estimated the mechanical advantage of the two primary masticatory muscles, the 125 temporalis and the masseter. These two muscles are particularly relevant as they are optimized to 126 generate force at different gape angles (masseter = low gape; temporalis = high gape; Cornette et al., 127 2013). Consequently, if shifts in prey size occur through time this may be reflected in the relative contribution on these two muscles to biting.

129

130

131

132

133

134

135

136

137

Human activity and its direct effects on islands, and in particular in Corsica, are well known. However, the full range of the underlying consequences of these impacts has not been extensively studied to date. In this paper, we investigated the effects of human-induced environmental changes in Corsica, taking as a case study the Etruscan shrew. We hypothesized that environmental changes will impact the integration of the mandible and tested whether phenotypic integration is a marker of environmental change in an archeological context. Integration (i.e. the link between different modules of the same anatomical structure) can change in two ways: via direct interactions (cell groupings or signaling pathways change) and via parallel variation due to selection on function (Klingenberg \& Zaklan 2000; Klingenberg et al. 2003; Klingenberg 2005). The first type of integration is difficult to change as it requires developmental and genetic "rewiring". The second type of integration mostly drives the evolution of population level variation (for example, Cheverud 1982, 1996; Wagner 1996; Wagner \& Altenberg 1996). Zelditch et al. (2009) suggested that while the mandible can be a highly modular system from a developmental point of view, it is a functionally integrated system as the mandible as a whole takes part in all its functions like the capture of prey and mastication. Here, we test whether the integration between the body and ramus of the mandible (Fig. 2a) changes in response to the rapid environmental changes observed at our study site through time. In summary, we attempt to define morpho-functional markers of environmental change due to human activity. More specifically, we test if, even over a short period of time at the start of the modern era the impact of environmental changes is visible on the phenotype of the mandible of Suncus etruscus, in terms of its form and function.

\section{Material \& Methods}

\subsection{Material}

We here focus on the modern era $\left(14^{\text {th }}-19^{\text {th }}\right.$ century AD), a short period of about 600 years. During this time interval, Vigne \& Valladas (1996) identified twelve layers at Monte di Tuda, each corresponding to a different depth in the sediment (Fig. 1C). They dated layer eleven at 1224-1459 AD (610 \pm 120 years $\mathrm{BP}$ ) and related the other layers with historical events, more specifically layer ten with the end of the war of Pisa (1556 AD), layer six with the agricultural development of the Genovese people (1637-1639 
AD; Arrighi, 1990) and layer three to the last cultivation optimum of the 19th century in Corsica (Vigne

156 \& Valladas, 1996). This period is characterized by a good resolution of environmental changes and

157 human activity through time and shows a gradual intensification of human activity, the predominance

158 of human transformed environments, and a short period of colder and wetter climate called the "Little

159 Ice Age" ( 1300-1850 AD) with minimal temperatures occurring around 1645-1715 AD; (Le Roy Ladurie,

160 1967; Lamb, 1969; Schneider \& Mass, 1975; Fagan, 2002).

161 We included 411 complete and fragmented mandibles (Appendix A.1) coming from the twelve different layers of the Monte di Tuda site (also included in the study of Vigne \& Valladas, 1996). We also included 26 present-day mandibles from different localities (Appendix A.2).

\subsection{Methods}

165

Specimens were sorted, numbered and the lingual sides were photographed using a NIKON D5500 camera (with a NIKKOR 60mm lens).

\subsubsection{Fragment types}

We categorized our specimens by fragmentation pattern and defined fragment types in order to include a maximum number of specimens in our analysis. We defined different fragment types described in Table 1 and Fig. 2b. Fragment types were based on Cornette et al. (2015a, b) and divided in types SC, COMP, CMM, ABC, MM. For the present study we also added types $A$ and $B$ (Fig. 2b). For fragments COMP, CMM and $B$ we also added sub-categories for the presence of the anterior part of the mandible (CMMi, $\mathrm{Bi}$ ) and the angular process (COMPan) (Fig. 2b).

\begin{tabular}{|l|l|}
\hline Groups & Anatomical localization \\
\hline $\mathrm{C}$ & Complete mandibles \\
\hline $\mathrm{SC}$ & Mandibles missing the angular process \\
\hline $\mathrm{SCC}$ & $\mathrm{SC}$ missing the posteroventral curvature \\
\hline COMPan & Mandibles missing the anterior part \\
\hline COMP & COMPan missing the angular process \\
\hline $\mathrm{CMMi}$ & Mandibles missing the angular and coronoid processes \\
\hline $\mathrm{CMM}$ & CMMi missing the anterior part \\
\hline $\mathrm{ABC}$ & Mandibles including the coronoid and angular processes \\
\hline $\mathrm{Bi} 1$ & $\begin{array}{l}\text { Mandibles missing the angular and coronoid processes as well as the articular } \\
\text { condyle }\end{array}$ \\
\hline $\mathrm{Bi}$ & Bi1 missing the posteroventral curvature \\
\hline
\end{tabular}




\begin{tabular}{|l|l|}
\hline B & $\begin{array}{l}\text { Mandibles only containing the medial parts along with the anterior corner of the } \\
\text { coronoid fossa }\end{array}$ \\
\hline A & Mandibles only containing the anterior part \\
\hline MM & $\begin{array}{l}\text { Very fragmentary specimens containing a fragment of the middle of the } \\
\text { mandible containing the } \mathrm{m} 1 \text { and } \mathrm{m} 2 \text { tooth insertions }\end{array}$ \\
\hline
\end{tabular}

174 Table 1. Anatomical localisation and description of the different fragment types starting with complete specimens 175 and finishing with the most fragmented types.

$176 \quad 2.2 .2$ Analysis of mandible shape

177 The description of shape was performed using geometric morphometrics, and more specifically the use 178 of anatomical landmarks and semi-landmarks on curves (Bookstein, 1997; Gunz et al., 2005; Cornette et 179 al., 2013). Semi-landmarks were slid using a bending energy minimization procedure and can thus be 180 considered spatially homologous (Bookstein, 1997; Slice, 2007; Mitteroecker \& Gunz, 2009). 

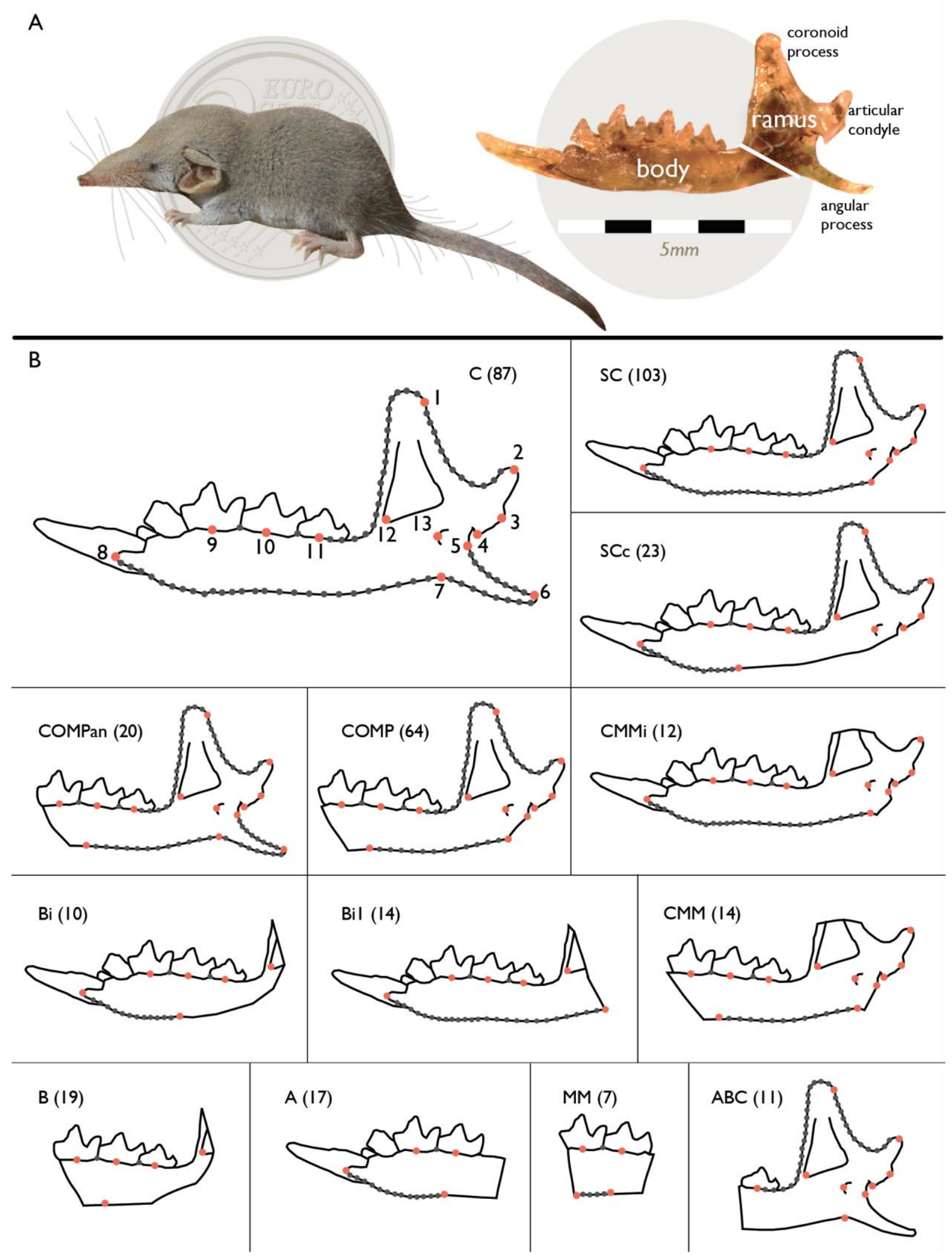

Figure 2. (a) Suncus etruscus (photographed by (C) Jose B. Ruiz) with a scale that corresponds to a 2-Euro coin and the anatomical parts of its mandible. (b) Types of fragments and their landmarks (red) and semi-landmarks (grey). The number in brackets corresponds to the number of specimens of each fragment type. 


\begin{tabular}{|l|l|}
\hline 1 & Maximum curve point of coronoid process \\
\hline 2 & \multirow{2}{*}{$\begin{array}{l}\text { Dorsal most, posteroventral and ventral } \\
\text { most aspect of the articular condyle }\end{array}$} \\
\hline 4 & Ventral point of condylar neck \\
\hline 6 & Most distal point of angular process \\
\hline 7 & $\begin{array}{l}\text { Inflexion point between angular process } \\
\text { and body of mandible }\end{array}$ \\
\hline 8 & Most anterior point of mandible body \\
\hline 9 & Intersection point of mandible and $\mathrm{m} 1$ \\
\hline 10 & Intersection point of mandible and $\mathrm{m} 2$ \\
\hline 11 & Intersection point of mandible and $\mathrm{m} 3$ \\
\hline 12 & Anterior corner of coronoid fossa \\
\hline 13 & $\begin{array}{l}\text { Anterior most point of mandibular } \\
\text { foramen }\end{array}$ \\
\hline
\end{tabular}

Table 2. Anatomical Landmarks and their description.

187 More specifically, 13 landmarks (Table 2) and 76 semi-landmarks were defined on complete specimens. 188 For fragmented mandibles we used the maximum number of landmarks present on the fragment (Fig. 1892 2b). A repeatability test was performed on three specimens. Landmarks were positioned 20 times on 190 each specimen, followed by a General Procrustes Analysis (GPA) and a Principal Components Analysis 191 (PCA). This showed that the intra-specimen variability was lower than that between specimens.

192 Landmark digitization was done using the TPSDig2 software (Rohlf, 2010). The definition and sliding of 193 semi-landmarks, Procrustes superimposition (by Bending energy) and PCA were done with the 194 'Geomorph' package (Adams et al., 2017) in R (R Development Core Team).

\section{$195 \quad$ 2.2.3 Neighbour-Joining trees of mean shapes}

We performed a 'Between group PCA' (i.e. a PCA on the mean shapes of each layer; Boulesteix, 2005; Mitteroecker \& Bookstein, 2011) for each fragment type (Appendix B.1) as this allows to minimize the shape variability within each layer and maximizes the variability between layers. This was done using the 'GroupPCA' function in the 'Morpho' R package (Schlager, 2017). In order to better visualize the morphological similarities between the layers and to take into consideration the total shape variability we created Neighbour-Joining trees (Saitou \& Nei, 1987; Studier et al., 1988) based on the Euclidian distances between the mean shapes of each layer using the ' $n j$ ' function of the 'ape' R package (Paradis et al., 2004). We did this for all fragment types, each time including the most complete specimens.

\subsubsection{Mechanical Potential}

We calculated the mechanical potential (MP) of the temporalis and masseter muscles on the complete specimens as well as on the fragment types that allowed for these calculations (i.e. SC, SCc, COMP and 
COMPan). We then calculated the mean for each layer. The MP of the temporalis was calculated

208 following two methods. The first (MPtemp; figure 3a) is the method described by Carraway et al. (1996;

209 see also Cornette et al., 2012, 2015c). Although this method has been widely used, it is not the best

210 estimation of force transmission by the temporalis muscle as it does not present the line of action of

211 the temporalis muscle realistically. As shown in figure 3a, in the original model, the temporalis bite

212 force (arrow) originates from the tip of the coronoid process and extends dorso-posteriorly. However,

213 in reality, the muscle attaches on the middle of the ramus and on the temporal bones of the skull that

214 are situated posterior to the coronoid process. This is the reason why we introduce the second method

215 referred to as MPtemp' (Fig. 3b) which provides a better estimate of the functional advantage of the

216 temporalis muscle by including the calculation of the muscle moment arm.
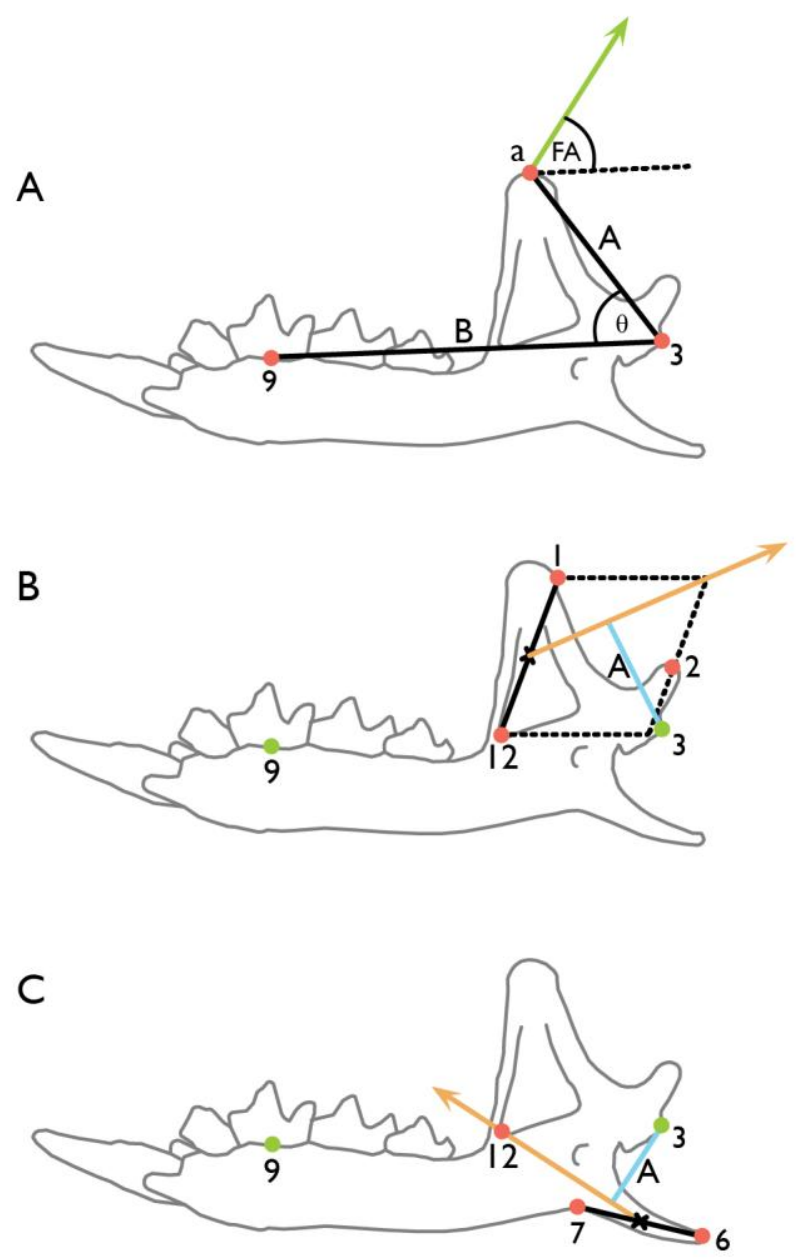

218 Figure 3. The biomechanical model of (a) MPtemp (by Carraway et al. 1996); (b) the new model for MPtemp' and

219 (c) MPmas. For all models, $B$ is the distance between landmark 3 and 9 (it is only represented in 3a because of lack

220 of free space in the rest). Distance $A$ is the distance between landmark 3 and the uppermost point of the coronoid

221 process for (a), the perpendicular distance between landmark 3 and the muscle vector (orange) for (b) and (c). FA

$222=90^{\circ}-\theta^{\circ}$. 
223 The mechanical potential of the masseter is calculated for the complete specimens as well as the

224 COMPan fragment using the method described below (Fig. 3c). For all analyses we used the $\log _{10}$

225 transformed mechanical potential values.

$226 \quad$ 2.2.4.1 MPtemp

227 Based on Carraway et al. (1996) the mechanical potential of the temporalis muscle is calculated with 228 the following function (see also figure 3a).

$$
\text { MPtemp }=(A / B) \text { cosine }(F A) \text { where } F A^{\circ}=90-\theta^{\circ}
$$

\subsubsection{MPtemp'}

231 We calculated the moment arm of the temporalis muscle by creating a vector that takes its origin at the 232 mid-point between landmarks 1 and 12 and whose direction is defined by the intersection of the 233 parallel passing through landmarks 2 and 3 (Fig. 3b). The perpendicular between the center of rotation 234 and this vector provides the moment arm of the temporalis muscle. This assumes no variation in the origin of the muscle on the cranium. The moment arm is dependent on the inclination of the coronoid process relative to the axis of the mandible.

$$
\text { MPtemp' }=\mathrm{A} / \mathrm{B}
$$

This is a model of the estimation of the masseter moment arm (Fig. 3c). We calculated the moment arm of the masseter by creating a vector which takes its origin at the mid-point between landmarks 6 and 7 and who's direction is defined by the position of landmark 12 (Fig. 3c). The perpendicular between the center of rotation and this vector provides the moment arm of the masseter muscle. The moment arm is dependent on the shape, length and position of the angular process relative to the axis of the mandible.

$$
\text { MPmas }=A / B
$$

\subsubsection{Mandible Size}

We used the centroid size to study size differences between mandibles of different layers and used the $\log _{10}$ transformed centroid size in our analyses. Centroid size equals the square root of squared distances of all landmarks of a mandible from its centroid (center of mass, whose position is calculated by the mean of the $x$ and $y$ coordinates of all landmarks; Klingenberg, 2016). 
252 To evaluate the effect of MPtemp, MPtemp', size, and the layers on the shape of the complete 253 specimens we performed a 'Procrustes ANOVA' (Goodall, 1991) using the 'procD.Im' of the R package 254 'Geomorph' (Adams et al., 2017). To understand what shape variation corresponds to mechanical 255 potential and size variation we visualized shapes corresponding to maximum and minimum MPtemp 256 and MPmas and size using multivariate regressions (Monteiro, 1999). Next, we also visualized allometry. The presence of allometry indicates the existence of an effect of size on shape (Huxley, 1924; Huxley et al., 1932; Cock, 1966; Gould, 1966; Calder, 1984; Schmidt-Nielsen, 1984; Klingenberg, 2016). Visualizations were done with the 'plotRefToTarget' function of the R package 'Geomorph' (Adams et al., 2017).

To evaluate the effect of size as well as vegetation and anthropisation indexes on MPs we performed simple regressions. To test the relation between MPtemp and MPtemp' and MPtemp' and MPtemp with MPmas we performed correlations (Pearson's correlation) for each case. Regressions and correlations were done using the 'Im' et 'cor' functions in R. To study how MPs and size change through time, we calculated the mean of each layer and presented box-plots (Appendix B.3) in order to present variation between each layer.

In order to study modularity and integration of the mandible, we first defined the body and ramus as the two modules of the mandible (Fig. 2a) based on previous studies (Cheverud et al., 1997; Mezey et al., 2000; Klingenberg et al., 2003). We performed a modularity test ('Modularity.test' function of the 'Geomorph' package; Adams et al., 2017) to compare the degree of modularity between two modules defined using the covariance ratio or CR coefficient (Adams, 2016). If the CR coefficient obtained by our pre-defined structure is smaller than the CRs obtained by the random permutations, then our hypothesis is valid (Adams, 2016). The definition of the modules was performed using the 'define.modules' function in 'Geomorph' (Adams et al., 2017). In order to test whether modules are integrated we performed an integration test using the 'Integration.test' function of 'Geomorph' (Adams et al., 2017). The two-block partial least squares (2b-PLS) test quantifies the degree of integration between the two modules (Adams \& Collyer, 2016). In addition, we visualized the shape of each module corresponding to the maximum and minimum of each axis of covariation using the 'shape.predictor' function of 'Geomorph' (Adams et al., 2017). In order to test functional consequences of integration we plotted all variables (MPs, size, vegetation and anthropisation indexes) on the first PLS axis. P-values were considered significant if smaller than or equal to 0.05 . For the analyses that include multiple tests/comparisons, we applied a Bonferroni correction according to which alpha (critical value) is used to judge the significance of the results and is equal to 0.05 divided by the number of tests performed for each analysis (Rice, 1989). 


\section{Results}

\section{$286 \quad 3.1$ Global morphological patterns}

287 The Euclidian distance tree for complete specimens is represented in figure $4 a$ and the rest are

288 represented in Appendix B.1. The tree in figure 4a shows a separation of the layers that correspond to a 289 recolonization of vegetation or high vegetation (nine and two) in contrast to layers characterized by a

290 high degree of anthropisation (one, three, and ten). Layers five and six correspond to the "Little Ice 291 Age" and are characterized by the presence of very low vegetation (Vigne \& Valladas, 1996). The 292 mandibles of the first group have a more posteriorly slanted coronoid process, a more anterior articular 293 condyle and a more ventral angular process while those of the third group have a shorter body and a 294 more anterior coronoid process. 

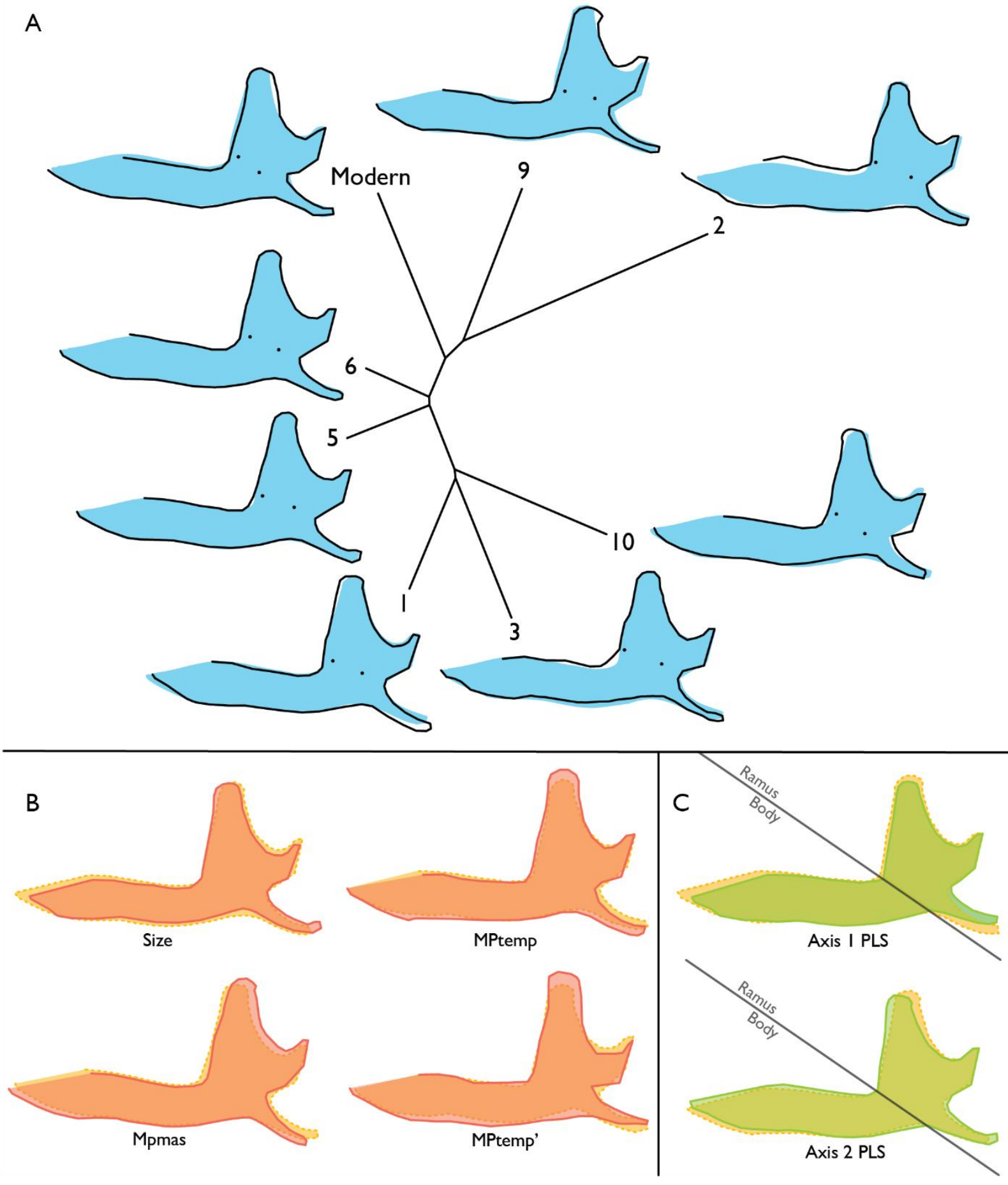

Figure 4. (a) The Euclidian distance tree between mean shape by layer for complete specimens (mean shapes by layer are also presented (black outline) and compared to mean shape of all sample (blue shape)); (b) The theoretical shape that corresponds to the minimum (yellow) and maximum (red) of size, MPtemp, MPtemp' and MPmas; (c) the theoretical shapes corresponding to the max (green) and minimum (yellow) of the first two PLS axis. Additional graphs in Appendix B.4.

Similar patterns emerge from trees established and based on different fragment types (Appendix B.1) including the distinction of layers eleven and seven, the grouping of layers five and six (trees SC, SCC, $\mathrm{CMMi}, \mathrm{ABC}, \mathrm{Bi})$, and the distinction of layers two and ten from layers five and six (COMP, COMPan, SC, 
all layers with low vegetation from layers two and eleven with high vegetation and trees (Vigne \&

307

308

309

310

311

312

313

314

315

316

317

318

319

320

321

322

323

324

325

326

327

328

329

330

331

332

333

334

335

336

337

Valladas, 1996). The SCc tree separates all layers from the layers nine and ten that correspond to cereal cultivation and its recolonization period (Vigne \& Valladas, 1996). The CMM tree (including COMP) separates all layers from layers four, three and eleven, the first corresponding to maximum vegetation and the two others to minimum vegetation (Vigne \& Valladas, 1996). Finally, the ABC tree (including COMP, COMPan, SC and C) separates all layers from layer seven (very humid climate and "Little Ice Age") and eleven (vegetation minimum) (Vigne \& Valladas, 1996).

\subsection{Morphological changes and functional consequences}

A summary of the statistical analyses performed as well as their results can be found in Appendix B.2. The results of the Procrustes ANOVA show a significant effect of layers $\left(P<0.001, R^{2}=0.13\right)$ and MPtemp $\left(P<0.001, R^{2}=0.06\right)$ on shape. MPmas impacted shape only before the application of the Bonferroni correction. To understand the nature of the effect of the mechanical potential and size on shape, we calculated the theoretical shapes corresponding to the maximum and minimum values of the variables (Fig. 4b).

The shape corresponding to maximum size presents a shorter and finer ramus, a more anterior coronoid, a more ventral articular condyle and a more stretched angular process (Fig. 4b). The shape corresponding to the maximum MPtemp has a more curved anterior ramus, a more robust and elongated coronoid and a more ventral angular process (Fig. 4b). The shape corresponding to the maximum MPtemp' is similar to the latter but with a more sharply dorsally and ventrally defined articular condyle and a posteriorly thinner, less ventrally positioned angular process. Finally, the shape corresponding to the maximum MPmas presents a narrower body, a more posterior coronoid, a more ventral articular condyle and a less robust and posterior and ventral angular (Fig. 4b). The changes in shape have consequences on the mechanical potential, something that was expected, as we found that $6.5 \%$ of shape variability is explained by MPtemp and $4.2 \%$ by MPmas.

Our results also show a significant effect of size on MPmas $\left(P=0.01, R^{2}=0.06\right)$, a negative correlation between MPtemp and MPmas $(P=0.03, r=-0.23)$, between MPtemp' and MPmas $(P=0.023, r=-0.25)$ as well as a strong positive correlation between MPtemp' and MPtemp $(P<0.001, r=0.44)$. The regression results show an effect of the anthropisation index on MPtemp' $(P=0.03, r=-0.04)$ and MPtemp $(P=0.001, r=-0.01)$, both decreasing with an increase in anthropisation.

\subsection{Mechanical potential and size through time}

The presentation of the mean MPtemp, MPtemp', MPmas, and size of complete and SC specimens by layer is found in figure 5 (a box-plot version is found in Appendix B.3). The MPtemp of layers three, 
seven and eleven seem to be different from other layers. There is a noticeable difference in MPtemp and MPtemp' between layers eleven and ten, however, the sample size for layer eleven is low. Notably,

340 the MPtemp' for samples from layers six to four is significantly different to that for the next most recent 341 layer. The MPtemp value for layer nine is significantly different than that of layer seven, and the latter is 342 significantly different than the value of the next most recent layer. MPmas increases when MPtemp 343 decreases (with the exception of layers five and six). However, there are missing values for several 344 layers and the only significant difference between MPmas values is that between layer three and nine.

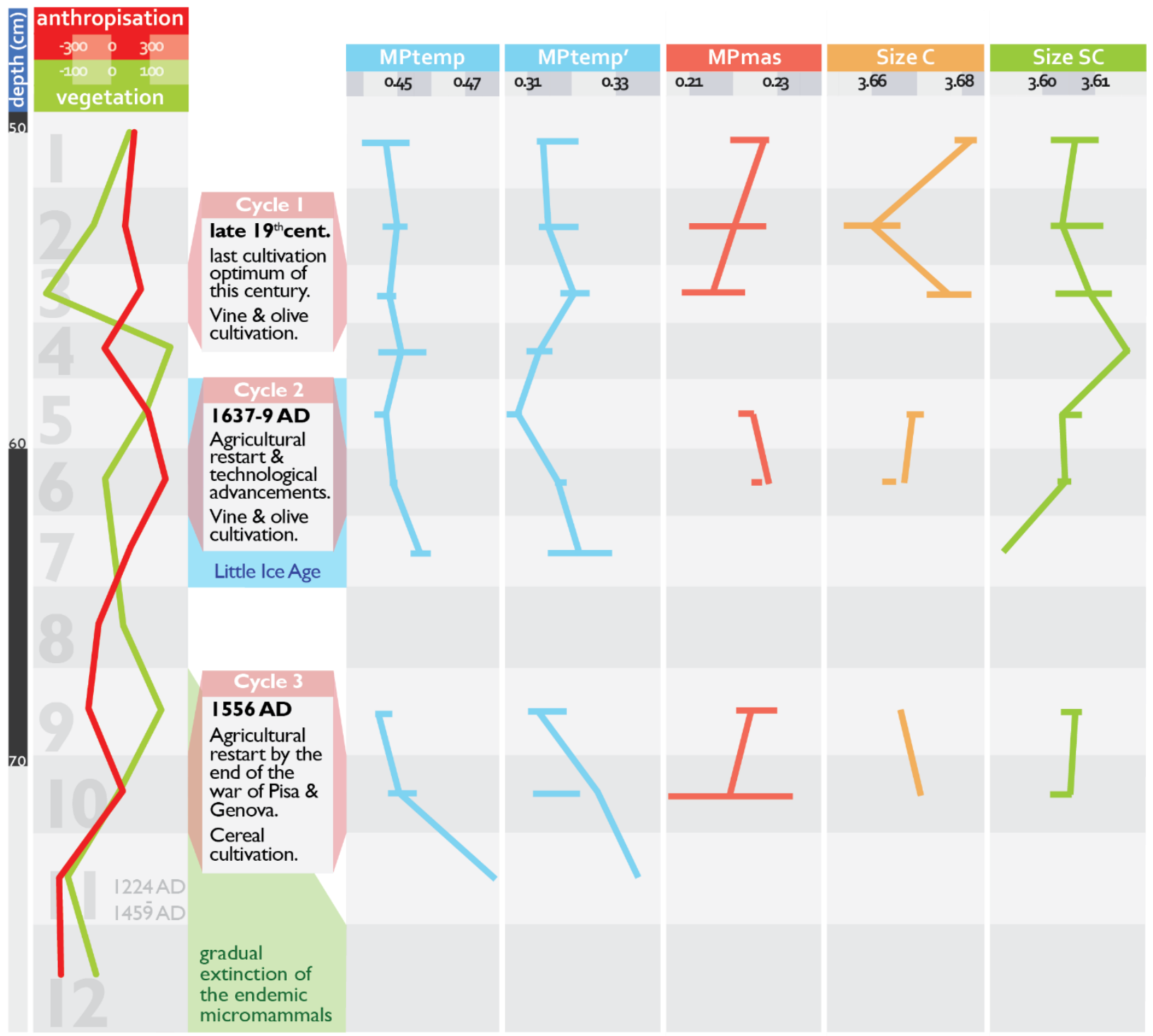

346 Figure 5. The mean values of MPtemp, MPtemp', MPmas and size (C and SC) by layer and compared to 347 anthropisation and vegetation indices and important historical events by layer (Vigne \& Valladas, 1996). Error bars 348 present the standard error of the mean (SE).

349 Regarding size, there are changes through time especially for fragment C. All the layers where enough samples were present to allow an estimate of error show that they are distinct from their adjacent 
samples. The SC fragments are recovered from most layers and as such provide a more complete image of changes over time. However, as the error bars overlap, no changes are present over time.

A summary of the analyses as well as supplementary graphs are found in Appendix B.2 and B.4. There is a statistically significant independence between the two modules of the mandible (body and ramus) $(P$ $<0.001, C R=0.67)$ compared to random divisions of the mandible. The integration results on the totality of the samples show that the two modules are integrated $(P<0.001, r-P L S=0.729)$. The integration tests on each layer find similar levels of integration in the layers tested (Appendix B.2). The first PLS axis that explains $50.6 \%$ of the total co-variation shows that when the coronoid process is more robust, the angular becomes more ventral and the body more stretched.

In order to test whether morphological changes of the two modules have functional consequences, we visualized the values of MPtemp, MPtemp', MPmas, size, layers as well as anthropisation and vegetation indices on the first PLS axis plot (Appendix B.4). No clear separation of groups appears on the PLS plot suggesting that the patterns of covariation are common to all groups. However, some grouping can be observed relative to the mechanical potential of the temporalis with animals with a higher MP segregating on the upper part of the PLS plot (Appendix B.4). Moreover, the maximum and minimum theoretical shapes of MPtemp (Fig. 4b) can be considered presenting similarities (mostly relative to the articular condyle) to the ones corresponding to the min and max of the first PLS axis (Fig. $4 c)$.

\section{Discussion}

371 Our results show that even over a short period of time environmental changes may result in rapid

372 changes of mandible shape (i.e. in the phenotype) in a small insectivorous mammal (Suncus etruscus).

373 As such, the shape of the mandible appears a good indicator of environmental change (Anderson et al.,

374 2008). Shape was linked with the mechanical potential of the temporalis muscle (MPtemp) and this

375 (MPtemp and MPtemp') was linked to changes in anthropisation. These results show that shape 376 changes have functional consequences that most probably are linked to shifts in diet that, in turn, have 377 taken place due to habitat alteration mostly because of the changes in human activity or anthropisation 378 around the study area. The morphofunctional relations observed in the present study (Fig. 4b) agree with those observed for other shrews. For example, Cornette et al. (2015c) also found a shorter mandible and Cornette et al. (2012) found a less robust body and more elongate angular process corresponding to an increased size. 
to the maximum mechanical potential of the temporalis muscle, similarly to our results. However, these relations were not investigated in relation to anthropisation changes. Additionally, our results extend the knowledge on how the shape of the shrew mandible reacts to functional constraints imposed by the masseter. The mechanical potential for the masseter muscle was not linked to any of the environmental variables and only slightly impacted by variation in size. It is noteworthy to mention that the MPmas was calculated for a significantly fewer number of specimens (compared to that of the temporalis) because it requires the presence of the angular process - a mandible part that is easily broken off and thus rarely preserved. In this study, we used two biomechanical models to calculate the mechanical potential of the temporalis muscle, one previously established (Carraway et al. 1996) and one that we thought was more representative of the muscle insertion and orientation. The estimates are, as expected, highly correlated. However, the results of the Procrustes ANOVA did not detect a significant link between shape and MPtemp'. If it is true that MPtemp' is a better representation of the function of the temporalis muscle than MPtemp, then this suggests that variation in MPtemp is not a direct consequence of changes in shape. As such it may represent a more general shape change in the coronoid rather than being linked specifically to the function of the temporalis muscle.

\subsection{Modularity and Integration}

Contrary to the mechanical potential, the integration of the two modules, body and ramus, does not appear to be a marker of environmental change (Fig. 4c, 5; Appendix B.2). Previous studies have shown that shifts in integration as a response to short-term environmental stress produced in the lab are possible in shrews (Badyaev \& Foresman 2004; Badyaev et al. 2005). The absence of integration shifts through time in our data suggests that either the environmental changes and diet change were not extreme enough to also alter the integration of the mandible during those 600 years (Klingenberg \& Zaklan 2000; Klingenberg et al. 2003; Klingenberg 2005) or that the mandible of Suncus etruscus is highly integrated functionally (as the mandible as a whole partakes in the capture and mastication of prey; Zelditch et al., 2009). It is also possible that integration change takes more time and would be visible only on a larger timescale (like for example Monteiro et al. 2005).

4.2 On the relation of mandible shape and size with environmental change

Our results suggest differences between layers as well as groupings of layers with similar environmental conditions. For example, layers three and ten or four and eleven correspond to the maximum and

412 minimum of the vegetation index (Fig. 4a and Appendix B.1). In addition, we found that these changes are rapid as shape differences are detected even in successive layers (ANOVA results and Fig. 5). This is of interest in the light of suggestions by previous authors (Sans-Coma et al., 1981) stating that Suncus etruscus is a relatively homeomorphic species in the Mediterranean and Europe in general, with the 
exception of Sardinia (Sans-Coma et al., 1985). Our results add the Corsican populations to that exception. Similarities between Sardinia and Corsica are not uncommon, because of their shared biogeographical past as well as their connection during periods of lower sea-level during the Pleistocene and the beginning of Holocene (Vigne, 1993; Oggiano et al., 2009).

Our results show a significant albeit low allometry as size explains only $2.5 \%$ of the total shape variability. Regarding variation in size through time, complete specimens show distinct sizes compared to the adjacent layers while incomplete SC specimens are less distinct in size (Fig. 5). However, it is interesting to note that layer four, corresponding to a vegetation maximum, and layer seven, corresponding to one of the "cold" periods during the "Little Ice Age" (along with layer six) have the biggest and smallest mandibles respectively. The fourth layer is characterized by the highest vegetation level and by a reduction in agricultural activity (Vigne \& Valladas, 1996). Large size could be an advantage to capture and eat larger prey, as is the case for bats (Santana \& Cheung, 2016), however, this remains to be tested. Bergmann's rule (see Bergmann, 1848; McNab, 1971) generally does not apply to shrews (Lomolino, 1985; Ochocinska \& Taylor, 2003) and the results of this study also support this as the smallest mandibles are found in the coldest intervals of our study. Ochocinska \& Taylor (2003) also observed smaller shrews in colder climates, especially for the smallest species of their study, Sorex minutus. They explained this observation by suggesting that a decrease in size may allow shrews to increase their ability to find better micro-habitats to survive (Randloph, 1973). Additionally, shrews lose a part of their mass during winter (Churchfield, 1990; Frafjord, 2008) and may change cranial shape seasonally and with age (Lázaro et al., 2017). As an exception, Zeveloff \& Boyce (1988) documented bigger shrews in colder climates but their study was spatially restricted to mostly cold habitats in Canada.

As previously mentioned, bite force is linked to diet in many animals (Aguirre et al., 2003; Anderson et al., 2008). Consequently, the study of the relative shifts of the mechanical potential of the temporalis and masseter muscles may provide information on the type of prey eaten. First, an increase in the mechanical potential of the muscles suggests an increase in bite force which may allow an expansion of

443 the dietary spectrum of an animal (i.e. allowing the animal to consume bigger or harder prey; Young et 444 al., 2007; Cornette et al., 2015c). A possible case where the reduction of the dietary spectrum could 445 have taken place is during layers six to five where the MP of both muscles seems to decrease (Fig. 5). 446 Second, an increase of masseter and decrease of temporalis mechanical potential, as in layers ten to nince, and three to two, suggests a shift in diet to one with more small/soft prey (Cornette et al., 2013). The strong negative correlation of the mechanical potential of the temporalis and masseter also supports this. MP shifts in shrews have also previously been linked with shifts in diet (Cornette et al., 
450

451

452

453

454

455

456

457

458

459

460

461

462

463

464

465

466

467

468

469

470

471

472

473

474

475

476

477

478

479

480

481

482

483

2012). However, it is noteworthy that MP could also give an advantage in competition between individuals of the same or different species. Competition and aggression in shrews is common (mainly involving biting) as they are very territorial (Churchfield, 1990; Kirkland, 1991; Cornette et al., 2015b, 2015c). As such, competition can also be expected to drive an increase in the mechanical potential of the temporalis muscle, more specifically as during aggressive interactions biting likely takes place at large gape.

Climate and man are both important factors that cause drastic changes to the environment and may affect wildlife. Climate change involves fluctuations in the mean temperature and humidity of the area that affect vegetation and fauna. Changes in human activity, however, can be faster and can equally impact vegetation according to differences in land use. In both cases, changes in vegetation affect the availability of prey and the efficacy of predation which may lead to changes in diet (Geier \& Best, 1980; Churchfield, 1990). Human-induced vegetation shifts have been found to affect the phenotype of shrews (example Badyaev et al. 2000). In our study it remains difficult to prove which (climate or man) was the primary driver of the observed changes in shape through time. However, during the period of our study only one important climatic change event took place, the "Little Ice Age", restricted to the time that corresponds to layers seven to five. However, our results show continuous shifts in shape and mechanical potential from Medieval times to the late $19^{\text {th }}$ century AD. Vigne \& Valladas (1996) also found extensive shifts in small mammal abundances during that time. Knowing that that interval was characterized by the intense human activity on the northern part of Corsica (Vigne \& Valladas, 1996) this suggests that humans were the primary drivers of habitat change which may have resulted in changes in diet leading to selection on mechanical potential and resulting in changes in shape. More specifically, our results show that anthropisation (the presence of human activity or not) and not vegetation (the presence of natural medium maquis versus low vegetation found in man-made cultivation habitats) affects the mechanical potential of the temporalis. For example, the highest value of temporalis MP is found in the oldest layer (but the sample size is small). The mean MPmas appears to increase through time as well (Fig. 5), possibly suggesting a shift to a diet containing smaller prey (Cornette et al. 2013).

While human impacts on the Corsican habitats around Monte di Tuda were already present from the Roman period onwards (Vigne \& Marinval-Vigne, 1989; Istria, 1994; Vigne \& Valladas, 1996) they intensified/accelerated just before the $13^{\text {th }}$ century with a drastic deforestation (corresponding to the oldest layers of this study). This is illustrated by the Monte di Tuda mammal assemblage but also by the construction of a small castrum on the same hill in 1289 AD, known to have been used for agricultural and pastoral purposes in Corsica (Istria, 1994). In northern Corsica, the establishment of this intensification is marked by cycle 3 - but similar patterns/events took place in southwestern Corsica as 
484

485

486

487

488

489

490

491

492

493

494

495

496

497

498

499

500

501

502

503

504

505

506

507

508

509

510

511

512

513

514

515

516

well (Vella et al., 2019). This cycle coincides with the Pisa Peace and the subsequent human population increase in the whole of Corsica (Vigne \& Valladas 1996; Perry, 1967). However, the drastic and intensified deforestation wave was not only visible in Corsica but in the whole western Europe (in eastern Spain (Planchais \& Parra Vergara, 1984; Riera-Mora \& Esteban-Amat, 1994), Southern France (Planchais, 1985; Durand \& Vernet, 1987; Diot \& Laborie, 1989; Chabal, 1991; Durand, 1991; Durand \& Leveau, 2004), French Alps (Colardelle \& Vedrel, 1993), Puglia (Martin, 1984) and Sicily (Bossard-Beck, 1984)). It is interesting to note that this drastic intensification event is also coupled with the extinction of the small mammal endemics like Prolagus, Tyrrhenicola and Rhagomys (Vigne \& Valladas, 1996). The endemic extinctions have been linked to this intensification of agricultural activities of Corsicans in the area of Monte di Tuda (Vigne, 1987; Vigne \& Marinval-Vigne, 1991). At a larger spatial scale these extinctions are more likely to have taken place across a longer time period and to be linked to more than one factor (Vigne, 2014). It is also interesting to note that whereas the arrival of humans on Corsica eventually led to the extinction of endemic small mammals, it left other groups like reptiles almost unimpacted (Vigne \& Alcover, 1985; Vigne et al., 1997).

\subsection{Final thoughts and perspectives}

The presence of humans has been an important factor shaping the environment of Corsica since their first arrival; however, the intensity of their impact fluctuated through time (Vigne et al., 1997). The results of this study show that human activity in northern Corsica was so intense that its impact is visible on the shape of the mandible of the smallest mammal. The shape and mechanical potential of the main masticatory muscle appear to be indicators of the fluctuations in human activity in the region. This study focused on a local scale, but it is expected that the human impact may be detectable in the micromammal fauna of the rest of the island. Corsica can also serve as an analogue for what happened to the rest of the Mediterranean islands in the sense that the first arrival of man happened early and with this, the introduction of new animals and plants and the anthropisation of the environment (Vigne, 1992). However, each Mediterranean island also has its unique human-habitat evolution (Vigne, 1996). It would be interesting to explore whether human impacts can be detected on the fauna of other islands and whether other small mammals reacted to this impact in the similar ways to Suncus etruscus.

\section{Conclusion}

In a short period of only 600 years, human exploitation resulted in environmental changes on the island of Corsica that had important underlying effects on the fauna. Human-induced environmental change likely resulted in rapid changes in the morphology of the mandible in a small shrew, Suncus etruscus. The changes in shape had functional consequences as they are strongly related to changes in the mechanical potential of the primary masticatory muscle, the temporalis. Its negative correlation with 
the second most important masticatory muscle, the masseter, as well as their link with the anthropisation index suggest a shift in the diet of this shrew species through time linked to human activity. Finally, the integration of the two modules of the mandible seems to be linked to the function of the temporalis muscle but is not a reliable marker of human-induced environmental change.

\section{Acknowledgements}

This study was funded by an Investissement d'Avenir Project Labex BCDiv (ANR-10-LABX-0003). We would like to thank Dr. Violaine Nicolas-Colin for allowing us to use the collections of micro-mammals of the MNHN (Muséum National d'Histoire Naturelle), Dr Thomas Cucchi for giving us the opportunity to work on the specimens of this study, and Prof. Jean-Denis Vigne who led the expedition during which the material of this study was collected. We also thank the anonymous reviewers and the editor of this paper, Prof. Marcos Martinón-Torres, for their constructive feedback which has greatly improved this manuscript.

\section{References}

530

531

532

533

534

535

536

537

538

539

540

541

542

543

Adams D.C. (2016) Evaluating modularity in morphometric data: challenges with the RV coefficient and a new test measure. Methods in Ecology and Evolution, 7(5), 565-572. 10.1111/2041-210X.12511

Adams D.C. \& Collyer M.L. (2016) On the comparison of the strength of morphological integration across morphometric datasets. Evolution, 70(11), 2623-2631. 10.1111/evo.13045

Adams D.C., Collyer M.L., Kaliontzopoulou A. \& Sherratt E. (2017) Geomorph: Software for geometric morphometric analyses. $\mathrm{R}$ package version 3.0.5.

Aguirre L.F., Herrel A., Van Damme R. \& Mathyssen E. (2003) The implications of food hardness for diet in bats. Functional Ecology, 17(2), 201-212. 10.1046/j.1365-2435.2003.00721.x

Alcover J.A., Moyá-Solà S. \& Pons-Moyá J. (1981) Les Quimeres del Passat. Els Vertebrats Fossils del PlioQuaternari de les Balears i Pitiuses. Editorial Moll, Palma de Mallorca, Spain.

Anderson R.A., McBrayer L.D. \& Herrel A. (2008) Bite force in vertebrates: opportunities and caveats for use of a nonpareil whole-animal performance measure. Biological Journal of the Linnean Society, 93(4), 709-720. 10.1111/j.1095-8312.2007.00905.x

Anderson P.S., Renaud S. \& Rayfield, E.J. (2014) Adaptive plasticity in the mouse mandible. BMC Evolutionary Biology, 14(85), 1-9. 10.1186/1471-2148-14-85 
Arrighi P. (1990) Histoire de la Corse. Privat, Toulouse, France.

546

547

548

549

550

551

552

553

554

555

556

557

558

559

560

561

562

563

564

565

566

567

568

569

570

571

572

Atchley W.R. (1993) Genetic and developmental aspects of variability in the mammalian mandible. The Skull, 1, 207-247.

Badyaev A.V. \& Foresman K.R. (2004) Evolution of morphological integration. I. Functional units channel stress-induced variation in shrew mandibles. The American Naturalist, 163(6), 868-879. $10.1086 / 386551$

Badyaev A.V., Foresman K.R. \& Fernandes M.V. (2000) Stress and developmental stability: vegetation removal causes increased fluctuating asymmetry in shrews. Ecology, 81(2), 336-345. 10.1890/00129658(2000)081[0336:SADSVR]2.0.CO;2

Badyaev A.V, Foresman K.R. \& Young R.L. (2005) Evolution of morphological integration: Developmental accommodation of stress-induced variation. American Naturalist, 166, 382-395. 10.1086/432559

Barnosky A.D., Koch P.L., Feranec R.S., Wing S.L. \& Shabel A.B. (2004) Assessing the causes of Late Pleistocene extinctions on the continents. Science, 306, 70-75.

Barnosky A.D., Matzke N., Tomiya S., Wogan G.O.U., Swartz B., Quental T.B., Marshall C., McGuire J.L., Lindsey E.L., Maguire K.C., Mersey B. \& Ferrer E. (2011) Has the Earth's sixth mass extinction already arrived? Nature, 471, 51-57. 10.1038/nature09678

Bar-Yosef O. \& Tchernov E. (1966) Archaeological finds and the fossil faunas of the Natufian and microlithic industries at Hayonim cave (Wester Galilee, Israel): a Preliminary Report of the 1965, 1966 Seasons. Israel Journal of Zoology, 15, 104-140. 10.1080/00212210.1966.10688238

Bergmann C. (1848) Über die Verhältnisse der Wärmeökonomie der Thiere zu ihrer Grösse. Göttinger Studien, 3, 595-708.

Blois, J.L., \& Hadly, E.A. (2009) Mammalian Response to Cenozoic Climatic Change. Annual Review of Earth and Planetary Sciences, 37(1), 181-208. 10.1146/annurev.earth.031208.100055

Bookstein F.L. (1997) Landmark methods for forms without landmarks: morphometrics of group differences in outline shape. Medical Image Analysis, 1(3), 225-243. 10.1016/S1361-8415(97)850128

Bossard-Beck C. (1984) Le mobilier ostéologique et botanique. In J.-M. Pesez (Ed.) Brucato, Histoire et Archéologie d’un Habitat Médiéval en Sicile. Ecole Française de Rome, Rome, Italy, 615-671. 
Boulesteix A.L. (2005) A note on between-group PCA. International Journal of Pure and Applied Mathematics, 19, 359-366. 10.5282/ubm/epub.1767

Brothwell D. \& Jones R. (1978) The relevance of small mammal studies to archaeology. Research Problems in Zooarchaeology, Occasional Publications, 3, 47-57.

Calder W.A. (1984) Size, function, and life history. Courier Corporation, Massachusetts, United States.

Callebaut W. \& Rasskin-Gutman D. (2005) Modularity: understanding the development and evolution of natural complex systems. MIT press, Cambridge, United States.

Carraway L.N., Verts B., Jones M.L. \& Whitaker Jr J.O. (1996) A search for age-related changes in bite force and diet in shrews. American Midland Naturalist, 135(2), 231-240.

Ceballos G., Ehrlich P.R., Barnosky A.D., García A., Pringle R.M. \& Palmer T.M. (2015) Accelerated modern human-induced species losses: Entering the sixth mass extinction. Science Advances, 1(5), e1400253. 10.1126/sciadv.1400253

Chabal L. (1991) L'environnement végétal de I'habitat antique de La Galère (Ile de Porquerolles, Hyères, Var). Etude anthracologique. Documents d'Archéologie Méridionale, 14, 368-377.

Chaline J. (1979) Les modifications de paysages et de climats de la fin des temps glaciaires en France (domaine boréal) révélées par les migrations de rongeurs. Sonne ville-Bordes, 97-104.

Chen H.L. \& Koprowski J.L. (2018) Recent island colonization by an introduced shrew in the western Mediterranean. Hystrix, 29, 232-235.

Cheverud J.M. (1982) Phenotypic, genetic, and environmental morphological integration in the cranium. Evolution, 36(3), 499-516. 10.2307/2408096

Cheverud, J.M. (1996) Developmental integration and the evolution of pleiotropy. American Zoologist, 36(1), 44-50.

Cheverud, J.M., Routman, E.J., Irschick, D.J., 1997. Pleiotropic effects of individual gene loci on mandibular morphology. Evolution, 51(6), 2006-2016. 10.2307/2411021

Churchfield S. (1990) The natural history of shrews. Cornell University Press, Ithaca, United States.

Cock A. (1966) Genetical aspects of metrical growth and form in animals. The Quarterly Review of Biology, 41(2), 131-190. 10.1086/404940 
600

601

602

603

604

605

606

607

608

609

610

611

612

613

614

615

616

617

618

619

620

621

622

623

624

625

626

627

628

Colardelle M. \& Vedrel E. (1993) Les habitats du lac de Paladru (Isère) dans leur environnement. Maison des Sciences de l'Homme (Documents d'Archéologie Française), 40.

Cornette R., Baylac M., Souter T. \& Herrel A. (2013) Does shape co-variation between the skull and the mandible have functional consequences? A 3D approach for a 3D problem. Journal of Anatomy, 223(4), 329-336. 10.1111/joa.12086

Cornette R., Herrel A., Cosson J.-F., Poitevin F. \& Baylac M. (2012) Rapid morpho-functional changes among insular populations of the greater white-toothed shrew. Biological Journal of the Linnean Society, 107(2), 322-331. 10.1111/j.1095-8312.2012.01934.x

Cornette R., Herrel A., Stoetzel E., Moulin S., Hutterer R., Denys C. \& Baylac M. (2015a) Specific information levels in relation to fragmentation patterns of shrew mandibles: do fragments tell the same story? Journal of Archaeological Science, 53, 323-330. 10.1016/j.jas.2014.10.020

Cornette R., Stoetzel E., Baylac M., Moulin S., Hutterer R., Nespoulet R., El Hajraoui M.A., Denys C. \& Herrel A. (2015b) Shrews of the genus Crocidura from El Harhoura 2 (Témara, Morocco): The contribution of broken specimens to the understanding of Late Pleistocene-Holocene palaeoenvironments in North Africa. Palaeogeography, Palaeoclimatology, Palaeoecology, 436, 1-8. 10.1016/j.palaeo.2015.06.020

Cornette R., Tresset A., Houssin C., Pascal M. \& Herrel A. (2015c) Does bite force provide a competitive advantage in shrews? The case of the greater white-toothed shrew. Biological Journal of the Linnean Society, 114, 795-807. 10.1111/bij.12423

Darwin C. (1845) Journal of Researches into the Natural History and Geology of the Countries Visited During the Voyage of HMS Beagle Round the World: Under the Command of Capt. Fitz Roy. John Murray, London, United Kingdom.

Davis S.J.M. (1984) Khirokitia and its mammal remains. A Neolithic Noah's Ark in Fouilles récentes à Khirokitia (Chypre) 1977-1981. Mémoire de l'Institut Mauritanien de la Recherche Scientifique, 1, 147-162.

Diot M.F. \& Laborie Y. (1989) Palynologie et histoire urbaine. Essai sur la dynamique du paysage du ler au XVe siècle autour du site de Bergerac (Dordogne). Aquitania 7, 143-173.

Dobson M. (1998). Mammal distributions in the western Mediterranean: the role of human intervention. Mammal Reviews, 28, 77-78. 
Durand A. \& Vernet J.L. (1987) Anthracologie et paysages forestiers médiévaux: à propos de quatre sites languedociens. Annales du Midi, 99, 397-405.

631

632

633

634

635

636

637

638

639

640

641

642

643

644

645

646

647

648

649

650

651

652

653

654

655

656

Durand A. (1991) Paysages, terroirs et peuplements dans les campagnes du bas Languedoc (Xe-XIle s.). Thèse Doctorat Université Panthéon-Sorbonne, Paris, France.

Durand A. \& Leveau P. (2004) Farming in Mediterranean France and rural settlement in the Late Roman and Early Medieval periods: the contribution from archaeology and environmental sciences in the last twenty years (1980-2000). In Barcelo M. \& Sigaut, F. (Eds.) The making of Feudal Agricultures, the transgormation of the Roman World, Brill, 177-253.

Fagan B. (2002) The Little Ice Age: how climate made history (1300 - 1850). Basic Books (Perseus Group Books), New York, United States.

Frafjord K. (2008) Can environmental factors explain size variation in the common shrew (Sorex araneus)? Mammalian Biology-Zeitschrift für Säugetierkunde, 73(6), 415-422.

10.1016/j.mambio.2007.08.007

Garland T. \& Kelly S.A. (2006) Phenotypic plasticity and experimental evolution. Journal of Experimental Biology, 209, 2344-2361. 10.1242/jeb.022673

Geier A.R. \& Best L.B. (1980) Habitat selection by small mammals of riparian communities: evaluating effects of habitat alterations. The Journal of Wildlife Management, 44(1), 16-24. 10.2307/3808346

Goodall C. (1991) Procrustes methods in the statistical analysis of shape. Journal of the Royal Statistical Society. Series B (Methodological), 53(2), 285-339.

Goswami A. \& Polly P.D. (2010) Methods for studying morphological integration and modularity. The Paleontological Society Papers, 16, 213-243.

Gould S.J. (1966) Allometry and size in ontogeny and phylogeny. Biological Reviews, 41(4), 587-638.

Gunz P., Mitteroecker P. \& Bookstein F.L. (2005) Semilandmarks in three dimensions. In: Modern morphometrics in physical anthropology (ed. by Slice D.E.), pp. 73-98. Springer, Boston, United States.

Hanot P., Herrel A., Guintard C. \& Cornette R. (2017) Morphological Integration in the appendicular skeleton of two domestic taxa: the horse and donkey. Proceedings of the Royal Society B, 284(1864), 20171241. 10.1098/rspb.2017.1241 
Hanot P., Herrel A., Guintard C. \& Cornette R. (2018) The impact of artificial selection on morphological integration in the appendicular skeleton of domestic horses. Journal of Anatomy, 232(4), 657-673.

$$
\text { 10.1111/joa.12772 }
$$

Huxley J.S., Strauss R.E. \& Churchill F.B. (1932) Problems of relative growth. The Johns Hopkins University Press, London, United Kingdom.

Huxley J.S. (1924) Constant differential growth-ratios and their significance. Nature, 114, 895-896.

Istria D. (1994) Le castellu de Cotone et l'origine du terroir dans le Nebbio et la Marana. Mémoire Diplôme Etudes Approfondies Université Aix-Marseille, Aix-en-Provence, France.

Jürgens K.D. (2002) Etruscan shrew muscle: the consequences of being small. Journal of Experimental Biology, 205, 2161-2166.

Kingdon J., Happold D., Butynski T., Hoffmann M., Happold M. \& Kalina J. (2013) Mammals of Africa. A \& C Black, London, United Kingdom.

Kirkland Jr G.L. (1991) Competition and coexistence in shrews (Insectivora: Soricidae). The Museum of Southwestern Biology, University of New Mexico, New Mexico, United States.

Klingenberg, C.P. (2005) Developmental constraints, modules, and evolvability. In B. Hallgrmsson \& B. K. Hall (Eds.) Variation: A central concept in biology, Elsevier Academic Press, San Diego, U.S., 219-247.

Klingenberg C.P. (2008) Morphological integration and developmental modularity. Annual Review of Ecology, Evolution, and Systematics, 39, 115-132. 10.1146/annurev.ecolsys.37.091305.110054

Klingenberg C.P. (2016) Size, shape, and form: concepts of allometry in geometric morphometrics. Development Genes and Evolution, 226(3), 113-137. 10.1007/s00427-016-0539-2

Klingenberg C.P., Leamy L.J. \& Cheverud J.M. (2004) Integration and modularity of quantitative trait locus effects on geometric shape in the mouse mandible. Genetics, 166(4), 1909-1921. 10.1534/genetics.166.4.1909

Klingenberg, C.P., Mebus K. \& Auffray J.C. (2003) Developmental integration in a complex morphological structure: How distinct are the modules in the mouse mandible? Evolution \& Development, 5(5), 522-531. 10.1046/j.1525-142X.2003.03057.x.

Klingenberg C.P. \& Zaklan S.D. (2000) Morphological integration between developmental compartments in the Drosophila wing. Evolution, 54(4), 1273-1285. 
685

686

687

688

689

690

691

692

693 694

695

696

697

698

699

700

701

702

703

704

705

706

707

708

709

710

711

Kouvari M. \& van der Geer A.A.E. (2018) Biogeography of extinction: The demise of insular mammals from the Late Pleistocene till today. Palaeogeography Palaeoclimatology Palaeoecology, 505, 295304.

Lamb H.H. (1969) Climatic fluctuations. Elsevier, Amsterdam, The Netherlands.

Lázaro J., Dechmann D.K.N., LaPoint S., Wikelski M., \& Hertel, M. (2017) Profound reversible seasonal changes of individual skull size in a mammal. Current Biology, 27(20), R1106-R1107. 10.1016/j.cub.2017.08.055

Le Roy Ladurie G. (1967). Histoire du Climat Depuis l'An Mil. Flammarion, Paris, France.

Lomolino M.V. (1985) Body size of mammals on islands: the island rule reexamined. The American Naturalist, 125(2), 310-316. 10.1086/284343

Losos J.B., Warheitt K.I. \& Schoener T.W. (1997) Adaptive differentiation following experimental island colonization in Anolis lizards. Nature, 387, 70-73.

MacPhee R.D. \& Sues H.-D. (2013) Extinctions in near time: causes, contexts, and consequences. Springer Science \& Business Media, Berlin, Germany.

Martin J.-M. (1984) L'homme et le milieu en Pouille, au début du Moyen Age. Bulletin de l'Association des Géographes de France, 499, 15-23.

Marquet J.-C. (1989) Paléoenvironnement et chronologie des sites du domaine atlantique français d'âge Pléistocène moyen et supérieur d'après l'étude des rongeurs. Dijon, France.

McNab B.K. (1971) On the ecological significance of Bergmann's rule. Ecology, 52(5), 845-854. $10.2307 / 1936032$

Mezey, J.G., Cheverud, J.M. \& Wagner, G.P. (2000) Is the genotype-phenotype map modular? A statistical approach using mouse quantitative trait loci data. Genetics, 156, 305-311.

Mitteroecker P. \& Bookstein F. (2007) The conceptual and statistical relationship between modularity and morphological integration. Systematic Biology, 56(5), 818-836. 10.1080/10635150701648029

Mitteroecker P. \& Bookstein F. (2011) Linear discrimination, ordination, and the visualization of selection gradients in modern morphometrics. Evolutionary Biology, 38(1), 100-114. 10.1007/s11692-011-9109-8 
Mitteroecker P. \& Gunz P. (2009) Advances in Geometric morphometrics. Evolutionary Biology, 36(2),

Monteiro L.R. (1999) Multivariate regression models and geometric morphometrics: the search for causal factors in the analysis of shape. Systematic Biology, 48(1), 192-199. $10.1080 / 106351599260526$

Monteiro L.R., Bonato V. \& Dos Reis S.F. (2005) Evolutionary integration and morphological diversification in complex morphological structures: Mandible shape divergence in spiny rats (Rodentia, Echimyidae). Evolution \& Development, 7, 429-439. 10.1111/j.1525-142X.2005.05047.x

720

721

722

Nowak R.M. \& Paradiso J.L. (1999) Walker's Mammals of the World. Johns Hopkins University Press, Baltimore, United States.

Ochocinska D. \& Taylor J.R. (2003) Bergmann's rule in shrews: geographical variation of body size in Palearctic Sorex species. Biological Journal of the Linnean Society, 78(3), 365-381. 10.1046/j.10958312.2003.00150.x

Oggiano G., Funedda A., Carmignani L. \& Pasci S. (2009) The Sardinia-Corsica microplate and its role in the Northern Apennine Geodynamics: new insights from the Tertiary intraplate strike-slip tectonics of Sardinia. Italian Journal of Geoscience, 128(2), 136-138.

Olson E.C. \& Miller R.L. (1958) Morphological integration. University of Chicago Press, Chicago, United States.

Paradis E., Claude J. \& Strimmer K. (2004) APE: analyses of phylogenetics and evolution in R language. Bioinformatics, 20(2), 289-290. 10.1093/bioinformatics/btg412

Perry P.J. (1967) Economy, Landscape and Society in La Castagniccia (Corsica) Since the Late Eighteenth Century. Transactions of the Institute of British Geographers, 41, 209. 10.2307/621337

Pimm S.L. \& Brooks T.M. (2000) The sixth extinction: How large, where, and when. National Academy Press, Washington, United States.

Planchais N. \& Parra Vergara I. (1984) Analyse pollinique de sédiments lagunaires et côtiers en Langedoc, en Roussilon et dans la province de Castellon (Espagne); bioclimatologie. Bulletin de la Société Botanique Française, 131, 94-105. 
Planchais N. (1985) Analyse pollinique du remplissage holocène de la lagune de Canet (plaine du Roussillon, département des Pyrénées-orientales). Ecologia Mediterranea, 11, 117-127.

Price T.D., Qvarnströ A. \& Irwin D.E. (2003) The role of phenotypic plasticity in driving genetic evolution. Proceedings of the Royal Society B: Biological Sciences, 1433-1440. 10.1098/rspb.2003.2372

R Development Core Team: R: a language and environment for statistical computing. Version 2.81. R Foundation for Statistical Computing, Vienna 2008.

Randloph J.C. (1973) Ecological energetics of a homeothermic predator, the Short-tailed shrew. Ecology, 54(5), 1166-1187. 10.2307/1935587

Renaud S., Alibert P. \& Auffray J.-C. (2009) Mandible shape in hybrid mice. Die Naturwissenschaften, 96, 1043-1050. 10.1007/s00114-009-0563-4

Renaud S., Auffray J.C. \& De La Porte S. (2010) Epigenetic effects on the mouse mandible: common features and discrepancies in remodeling due to muscular dystrophy and response to food consistency. BMC Evolutionary Biology, 10(1), 28.

Rice W.R. (1989) Analyzing tables of statistical tests. Evolution, 43(1), 223-25.

Riera-Mora S. \& Esteban-Amat A. (1994) Vegetation history and human activity during the last 6000 years on the central Catalan coast (northeastern Iberian Peninsula). Vegetation History and Archaeobotany, 3, 7-23.

Rofes J., Murelaga X., Martínez-García B., Bailon S., López-Quintana J.C., Guenaga-Lizasu A., Ortega L.Á., Zuluaga M.C., Alonso-Olazabal A., Castaños J. \& Castaños P. (2014) The long paleoenvironmental sequence of Santimamiñe (Bizkaia, Spain): 20,000 years of small mammal record from the latest Late Pleistocene to the middle Holocene. Quaternary International, 339-340, 62-75. https://doi.org/10.1016/j.quaint.2013.05.048

Rohlf F.J. (2010) TpsDig2: digitize coordinates of landmarks and capture outlines. Department of Ecology and Evolution, State University of New York at Stony Brook, New York, United States.

Saitou N. \& Nei M. (1987) The neighbor-joining method: a new method for reconstructing phylogenetic trees. Molecular Biology and Evolution, 4(4), 406-425. 10.1093/oxfordjournals.molbev.a040454 
Sans-Coma V., Alcover J.A. \& Lopez-Fuster J. (1985) Morphometrischer Vergleich rezenter und subfossiler Etruskerspitzmäuse Suncus etruscus (Savi, 1822) von der Insel Sardinien. Säugetierkundliche Mitteilungen, 32, 151-158.

Sans-Coma V., Fons R. \& Vesmanis I. (1981) Eine morphometrische Untersuchung am Schädel der Etruskerspitzmaus, Suncus etruscus (Savi, 1822) aus Siid-Frankreich (Mammalia, Insectivora, Soricidae). Zoologische Abhandlungen - Staatliches Museum für Tierkunde in Dresden, 37, 1-31.

Santana S.E. \& Cheung E. (2016) Go big or go fish: morphological specializations in carnivorous bats. Proceedings of the Royal Society B, 283(1830), 20160615. 10.1098/rspb.2016.0615

Schlager S. (2017) Morpho and Rvcg - Shape Analysis in R: R-Packages for Geometric Morphometrics, Shape Analysis and Surface Manipulations. Elsevier, New York, United States.

Schlosser G. \& Wagner G.P. (2004) Modularity in development and evolution. University of Chicago Press, Chicago, United States.

Schmidt-Nielsen K. (1984) Scaling: why is animal size so important? Cambridge University Press, Cambridge, United Kingdom.

Schneider S.H. \& Mass C. (1975) Volcanic dust, sunspots, and temperature trends. Science, 190(4216), 741-746. 10.1126/science.190.4216.741

Slice D.E. (2007) Geometric morphometrics. Annual Review of Anthropology, 36, 261-284. 10.1146/annurev.anthro.34.081804.120613

Stoetzel E., Marion L., Nespoulet R., El Hajraoui M.A. \& Denys C. (2011) Taphonomy and palaeoecology of the late Pleistocene to middle Holocene small mammal succession of El Harhoura 2 cave (RabatTémara, Morocco). Journal of Human Evolution, 60(1), 1-33. 10.1016/j.jhevol.2010.07.016

Studier J.A., Keppler K.J. \& others (1988) A note on the neighbor-joining algorithm of Saitou and Nei. Molecular Biology and Evolution, 5(6), 729-731. 10.1093/oxfordjournals.molbev.a040527

Vella M.A., Andrieu-Ponel V., Cesari J., Leandri F., Pêche-Quilichini K., Reille M., Poher Y., Demory F., Delanghe D., Ghilardi M. \& Ottaviani-Spella M.M. (2019) Early impact of agropastoral activities and climate on the littoral landscape of Corsica since mid-Holocene. PLoS One, 14(12), e0226358. 10.1371/journal.pone.0226358 
Vigne J.-D. (1987) L'extinction holocène du fond (sic) de peuplement mammalien indigène des îles de Méditerranée occidentale. Mémoire de la Société Géologique de France, 150, 167-177.

Vigne J.-D. (1988) Les Mammifères du Post-Glaciaire de Corse. Etude archéozoologique. Gallia Prehistoire, 114 (suppl.), 186-187.

Vigne J.-D. (1990) Biogeographical history of the mammals on Corsica (and Sardinia) since the final Pleistocene. Atti dei Convegni Lincei, 85, 369-392.

Vigne J.-D. (1992) Zooarchaeology and the biogeographical history of the mammals of Corsica and Sardinia since the last ice age. Mammal Review, 22(2), 87-96.

Vigne J.-D. (1996) Did Man provoke extinctions of endemic large mammals on the Mediterranean Islands? The view of Corsica. Journal of Mediterranean Archaeology, 9(1), 117-120.

Vigne J.-D. (1999) The large "true" Mediterranean islands as a model for the Holocene human impact on the European vertebrate fauna? Recent data and new reflections. In: The Holocene history of the European vertebrate fauna: Modern aspects of research (ed. by Benecke N.), pp. 295-322. Deutsches Archäologisches Institut, Eurasien-Abteilung, Rahden/Westf: Verlag Marie Leidorf, Berlin, Germany.

Vigne J.-D. (2014) The origins of mammals on the Mediterranean islands as an indicator of early voyaging. Eurasian Prehistory, 10, 45-56.

Vigne J.-D. \& Alcover J.A. (1985) Incidence des rélations historiques entre l'homme et l'animal dans la composition actuelle du peuplement amphibien, reptilien et mammalien des îles de Mediterranée occidentale. Actes du 110ème Congrés National des Sociétés Savantes, 79-91.

Vigne J.-D., Bailon S. \& Cuisin J. (1997) Biostratigraphy of amphibians, reptiles, birds and mammals in Corsica and the role of man in the Holocene faunal turnover. Anthropologica, 25, 587-604.

Vigne J.-D. \& Marinval-Vigne M.-C. (1989) Faune. In P. Pergola \& C. Vizmara (Eds) Castellu, un établissement de l'Antiquité tardive en Corse. Maison des Sciences de l'Homme (Documents d’Archéologie Française) Paris, France, 115-147.

Vigne, J.-D. \& Marinval-Vigne, M.-C. (1991) Reflexions écologiques sur le renouvellement holocène des micromammiferes en Corse: les données préliminaires des fossiles du Monte di Tuda. In Le Berre M. \& Le Guelte M. (Eds) Le Rongeur et I'Espace. Chabaud, Paris, France, 183-193. 
Vigne J.-D. \& Valladas H. (1996) Small mammal fossil assemblages as indicators of environmental change in northern Corsica during the last 2500 years. Journal of Archaeological Science, 23(2), 199215.

Vitousek P.M., D’Antonio C.M., Loope L.L., Rejmanek M. \& Westbrooks R. (1997) Introduced species: a significant component of human-caused global change. New Zealand Journal of Ecology, 21(1), 1-16.

Wagner G.P. (1996) Homologues, natural kinds and the evolution of modularity. American Zoologist, 36(1), 36-43.

Wagner G.P. \& Altenberg L. (1996) Complex adaptations and the evolution of evolvability. Evolution, 50(3), 967-976. 10.2307/2410639.

Wallace A.R. (1860) On the zoological geography of the Malay Archipelago. Zoological Journal of the Linnean Society, 4(16), 172-184.

Weissbrod L. (2010) Biological indicators of occupation intensity: An environmental ethnoarchaeology of Maasai settlements. In: The Archaeology of Anthropogenic Environments (ed. by Dean R.M.), pp. 295-320. Carbondale: Center for Archaeological Investigations, Southern Illinois University, Illinois, United States.

Whittaker R.J. \& Fernández-Palacios J.M. (2007) Island biogeography: ecology, evolution, and conservation. Oxford University Press, Oxford, United Kingdom.

Young, R.L. \& Badyaev A.V. (2010) Developmental plasticity links local adaptation and evolutionary diversification in foraging morphology. Journal of Experimental Zoology Part B: Molecular and Developmental Evolution, 314 B(6), 434-444. 10.1002/jez.b.21349

Young R.L., Haselkorn T.S. \& Badyaev A.V. (2007) Functional equivalence of morphologies enables morphological and ecological diversity. Evolution, 61(11), 2480-2492. 10.1111/j.15585646.2007.00210.x

Young R.L., Sweeney M.J. \& Badyaev A.V. (2010) Morphological diversity and ecological similarity: versatility of muscular and skeletal morphologies enables ecological convergence in shrews. Functional Ecology, 24(3), 556-565. 10.1111/j.1365-2435.2009.01664.x

Zelditch M.L., Wood A.R. \& Swiderski D.L. (2009) Building developmental integration into functional systems: Function-induced integration of mandibular shape. Evolution \& Biology, 36, 71-87. 10.1007/s11692-008-9034-7 
848 Zeveloff S.I. \& Boyce M.S. (1988) Body size patterns in North American mammal faunas. In: Evolution of 849 life histories of mammals (ed. By Boyce M.S.), pp. 123-146. Yale University Press New Haven, 850 Connecticut, United States. 